\title{
USING CUTTLEBONE POWDER TO PRODUCE GREEN CONCRETE
}

\section{Sara Mirzabagheri ${ }^{a *}$, Ghazaleh Derhamjanib, Sahar Maharati ${ }^{b}$, Zeynab Ziaee ${ }^{b}$, F. Vatankhah $^{\text {b }}$, D. Mirzabagheri ${ }^{\mathrm{c}}$}

\author{
${ }^{a *}$ Civil Engineering Division, Faculty of Engineering, Parand Branch, Islamic Azad University, Parand, Tehran, Iran, \\ E-mail: sara_mirzabagheri@yahoo.com \\ ${ }^{\mathrm{b}}$ Young Researchers and Elite Club, Parand Branch, Islamic Azad University, Parand, Tehran, Iran \\ ${ }^{c}$ Young Researchers and Elite Club, Kerman Branch, Islamic Azad University, Kerman, Iran
}

Received: 26.07.2018 / Accepted: 15.09.2018 / Revised: 20.11.2018/ Available online: 15.12.2018

DOI: 10.2478/jaes-2018-0014

KEY WORDS: Green concrete, Eco-friendly concrete, Cuttlebone, Calcium carbonate, Compressive strength, Splitting tensile strength, Flexural strength.

\begin{abstract}
:
Limestone has been commonly used in concrete for several decades. Moreover, calcium carbonate was used as a portion of cement content. Therefore cuttlebone powder, which is composed of a naturally occurring crystal form of calcium carbonate named aragonite, was used in concrete as a substitution of a portion of cement content in this research program for the first time. It led to the production of green concrete which is a type of concrete causes less harm to environment. 3, 5 and 7 percent of cement were substituted with cuttlebone powder. For this purpose, 4 concrete mix designs included 36 cubes, 4 cylinders and 4 prisms were casted. Results showed that weight of the specimens with cuttlebone powder was lower than control specimen. Moreover, by adding cuttlebone powder to concrete, slump increased. Although compressive and tensile strengths of the specimens with cuttlebone powder were lower than control specimen, but the specimen with 3\% cuttlebone powder had adequate strength. Besides, three-point flexural strength of the concrete with $3 \%$ cuttlebone powder was higher than control specimen. It seems that by reducing water content of the specimen with cuttlebone powder to have similar slump to the control specimen, better performance of concrete can be achieved. So, this natural material can be used instead of a portion of cement to produce green concrete.
\end{abstract}

\section{INTRODUCTION}

Green concrete is a type of concrete with some materials as a partial or complete replacement for cement and/or aggregates. Cement is one of the main parts of concrete. In the procedure of producing cement, $\mathrm{CO}_{2}$ is emitted to air. Thus it leads to air pollution. Therefore, by substituting a portion of cement with other materials, air pollution decreases. Various materials were used to produce green concrete and their effect on concrete performance was evaluated. One of these materials is calcium carbonate $\left(\mathrm{CaCo}_{3}\right)$

The effect of using limestone powder in cement and concrete was evaluated in 2003 (Naik et al. 2003). It was concluded that usage of limestone powder not only had environmental advantages, but also improved compressive strength. A state of the art on the usage of combination of fly ash and limestone was reported by Weerdt (2007). It was proposed that if the fineness of the limestone filler was higher, its effect was stronger. Replacements up to $10 \%$ led to a more homogenous structure of the cement paste. In 2012, shell and $\mathrm{CaCo}_{3}$ were used in concrete by Wang et al. (2012). It was seen that compressive strength would have decreased if shell content had increased. A report by Tennis et al. (2014) was provided on the use of limestone in hydraulic cements in amounts between 5\% and
$15 \%$. It was reported that use of $12 \%$ limestone in concrete resulted in equivalent performance to concrete with Portland cement in Canada. Moreover, particle packing had effects on water demand and thus increased strength. The effect of calcium carbonate on performance of wood ash cement concrete was investigated by Okeyinka and Oladejo (2014). Results showed that calcium carbonate increased compressive strength of this type of concrete. Another investigation was conducted on the effect of nano- $\mathrm{CaCO}_{3}$ on compressive strength of concrete with high volume fly ash (Supit and Shaikh, 2014). Results showed that $1 \%$ nano- $\mathrm{CaCO}_{3}$ increased compressive strength of mortars and concretes. In 2015, limestone reaction in calcium aluminate cement-calcium sulfate systems was investigated (Bizzozero and Scrivener, 2015). Another investigation was conducted on the influence of fine limestone powder and conventional limestone aggregates on the performance of concrete (Bentz et al. 2015). It was seen that usage of $10 \%$ limestone resulted to acceptable performance of concrete. Moreover, compressive strength of alkali-activated lightweight concrete was investigated in 2017 (Wongkeo, 2017). This type of concrete was constructed by using fly ash, calcium carbonate and sodium hydroxide. Calcium carbonate was substituted a portion of fly ash. Besides, sodium hydroxide was used. It was concluded that compressive strength of lightweight concrete with calcium carbonate improved. Therewith, acceptable compressive

\footnotetext{
* Corresponding author: Sara MIRZABAGHERI, Assistant Professor, e-mail: sara_mirzabagheri@yahoo.com
} 
strength of alkali-activated lightweight concrete was seen. In 2017, mortar concretes with synthetic lightweight aggregates and in some cases carbonate calcium were tested (Ramos and Swan, 2017). Compressive strength of concrete with synthetic lightweight aggregates was reduced. By adding small quantities of $\mathrm{CaCO}_{3}$ partially increase in the strength was seen. Sui et al. (2018) tested reactive powder concrete with calcium carbonate concrete waste powder instead of silica fume. It was seen that strength of this concrete was not obviously reduced.

Another investigation on the use of natural materials in concrete was conducted by the authors and their colleagues in 2018 (Mirzabagheri et al. 2018). Albumen, yolk and camel milk with various percentages were used in concrete and their effect on concrete performance was studied.

In this research program another natural material i.e. cuttlebone powder which contains calcium carbonate was used instead of a portion of cement in concrete mixture to produce green concrete. Four concrete mixtures were designed. 36 cubes, 4 cylinders and 4 prisms were casted to test compressive strength, tensile strength and three-point flexural strength, respectively. Compressive strength test was conducted after 7, 14 and 28 days. Tensile and flexural strengths were tested after 28 days.

\section{MATERIALS AND METHODS}

Because of the environmental benefits of producing green concrete, in this research program cuttlebone powder was used instead of a portion of cement.

Cuttlebone is a hard brittle internal shell in all members of the family Sepiidae. It is also known as cuttlefish bone. Cuttlebones are utilized as calcium-rich dietary supplements for many animals such as caged birds, reptiles, shrimp, chinchillas, hermit crabs, and snails (Norman and Reid, 2000). It is composed primarily of aragonite which is a carbonate mineral (Rexfort and Mutterlose, 2006). Aragonite is one of the three most common naturally occurring crystal forms of calcium carbonate, $\mathrm{CaCO}_{3}$. Figure 1 shows cuttlebone.

In 2016, Waste cuttlebone was used in epoxy compositions as a filler material. Results showed that heat-treated cuttlebone reinforced epoxy composites had higher tensile properties than other composites (Periasamy and Mohankumar, 2016).

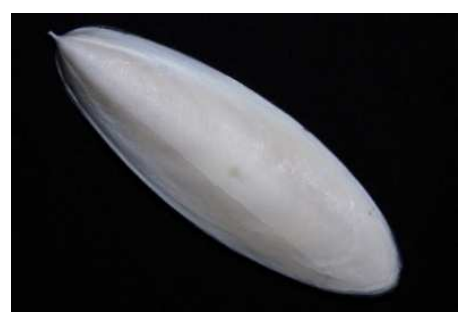

Figure 1. Cuttlebone

\subsection{Concrete Mix Proportions}

Four concrete mixtures were designed. One of the concrete mix designs named as $\mathrm{S}$ is a control mixture, while others contained cuttlebone powder. 3, 5 and 7 percent of cement content were substituted with cuttlebone powder. Table 1 represents mixture proportions.

Nine $15 \times 15 \mathrm{~cm}$ cube samples were casted for each concrete mix design to test compressive strength after 7, 14 and 28 days. In all of these concrete mixtures one standard cylinder and one beam with the size of $10 \times 10 \times 50 \mathrm{~cm}$ were casted to test tensile strength and three-point flexural strength, respectively. Curing procedure was performed till the day of testing. Figure 2 shows casted specimens in the laboratory.

Table 1. Concrete mix proportions

\begin{tabular}{c|c|c|c|c|c}
\hline Specimen & $\begin{array}{c}\text { Water } \\
\left(\mathrm{kg} / \mathrm{m}^{3}\right)\end{array}$ & $\begin{array}{c}\text { Cement } \\
\left(\mathrm{kg} / \mathrm{m}^{3}\right)\end{array}$ & $\begin{array}{c}\text { Fine } \\
\text { Aggregate } \\
\left(\mathrm{kg} / \mathrm{m}^{3}\right)\end{array}$ & $\begin{array}{c}\text { Coarse } \\
\text { Aggregate } \\
\left(\mathrm{kg} / \mathrm{m}^{3}\right)\end{array}$ & $\begin{array}{c}\text { Cuttlebone } \\
(\% \text { of } \\
\text { Cement })\end{array}$ \\
\hline $\mathrm{S}$ & 200 & 426 & 824 & 898 & - \\
\hline $\mathrm{K} 3$ & 200 & 413 & 824 & 898 & 3 \\
\hline $\mathrm{K} 5$ & 200 & 405 & 824 & 898 & 5 \\
\hline $\mathrm{K} 7$ & 200 & 396 & 824 & 898 & 7 \\
\hline
\end{tabular}

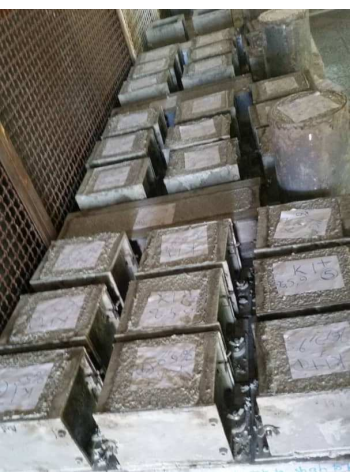

Figure 2. Casted specimens

\section{EXPERIMENTAL RESULTS AND DISCUSSION}

\subsection{Slump}

The concrete slump test shows the consistency and workability of fresh concrete. Therefore, slump test was done for each type of concrete. It was seen that the slump of control mixture was about $2 \mathrm{~cm}$. By adding cuttlebone powder to the mixture, slump increased to about $15 \mathrm{~cm}$. Because of the calcium carbonate of cuttlebone, slump increased. Thus, it could be resulted in reduction of water demand and subsequently increase of strengths.

\subsection{Weight}

After 7 days, the specimens of each type were weighed. Table 2 presents average weight of each type. As can be seen from the table, the specimens with cuttlebone powder had lower weight compared to the control specimens.

Table 2. Average weight of the specimens after 7 days

\begin{tabular}{c|c|c|c}
\hline $\mathrm{S}$ & $\mathrm{K} 3$ & $\mathrm{~K} 5$ & $\mathrm{~K} 7$ \\
\hline $7.94 \mathrm{~kg}$ & $7.65 \mathrm{~kg}$ & $7.22 \mathrm{~kg}$ & $7.20 \mathrm{~kg}$ \\
\hline
\end{tabular}

\subsection{Compressive Strength}

Cube specimens were tested after 7, 14 and 28 days. Three specimens were tested for each age. Figure 3 shows a specimen 
in the compressive test machine. Average of three specimens' strength is presented in Figure 4 for every concrete mixture.

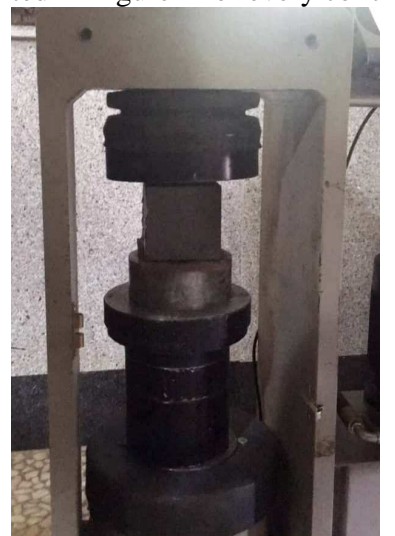

Figure 3. Compressive strength test

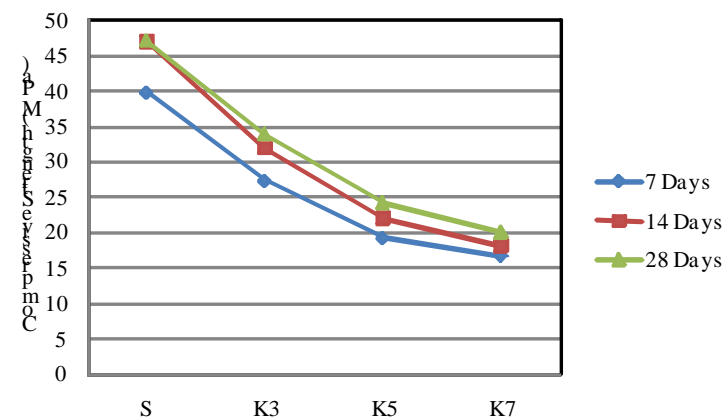

Figure 4. Compressive strength of the cube specimens

As can be seen in Figure 4, compressive strength of the specimens with cuttlebone powder was lower than control specimen. But the specimen with 3\% cuttlebone had acceptable strength. It is worth noting that, by adding cuttlebone powder to the concrete, water demand decreases and therefore strength increases. So, by adding this material to the mixture, water should be reduced.

\subsection{Splitting Tensile Strength}

Splitting tensile strength is one of the tests to achieve tensile strength of concrete. To achieve tensile strength a standard cylinder with the size of $15 \times 30 \mathrm{~cm}$ was tested for each mixture. The cylinder was placed horizontally in a special fixture and then was put in a universal testing machine as shown in Figure 5. Due to indirect tensile stress, the specimen splits into two halves.

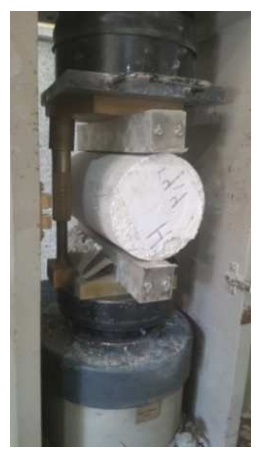

Figure 5. Tensile strength test
Splitting tensile strength of concrete is calculated based on Eq.1.

$$
f_{t}=\frac{2 p}{\pi D L}
$$

where,

$$
\begin{aligned}
& \mathrm{P}=\text { compressive load at failure } \\
& \mathrm{D}=\text { diameter of cylinder } \\
& \mathrm{L}=\text { length of cylinder }
\end{aligned}
$$

Figure 6 shows average splitting tensile strength of the specimens after 28 days. Descending trend was seen. But the value of splitting tensile strength of the specimen with $3 \%$ cuttlebone powder was acceptable.

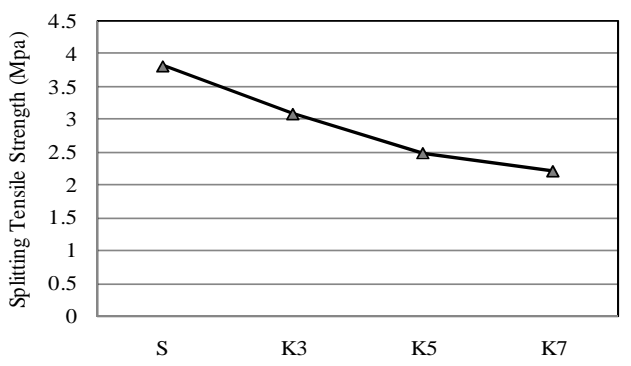

Figure 6. Splitting tensile strength of the specimens

\subsection{Three-Point Flexural Strength}

Three-point flexural test, which has a simple preparation and testing, is one of the important tests for evaluation of concrete performance. Each prism was placed in the fixture. Then the fixture was placed in the universal testing machine as shown in Figure 7. The specimen was placed on two pin supports and the load was applied at mid-span.

By using Eq. 2, flexural strength, $\sigma_{f}$, can be achieved.

$$
\sigma_{f}=\frac{3 F L}{2 b d^{2}}
$$

where,

$$
\begin{aligned}
& \mathrm{F}=\text { load at a given point } \\
& \mathrm{L}=\text { support span } \\
& \mathrm{b}=\text { width of the beam } \\
& \mathrm{d}=\text { depth of the beam }
\end{aligned}
$$

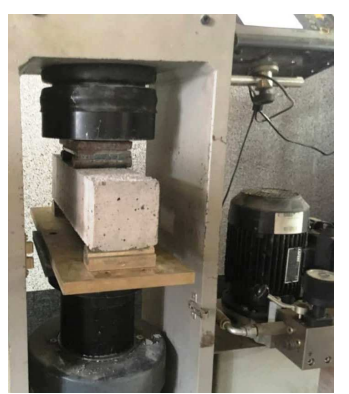

Figure 7. Three-point flexural strength test

Average of three-point flexural strengths for each mixture is presented in Figure 8. As can be seen, K3 specimen with 3\% cuttlebone powder had higher flexural strength compare to other specimens. 


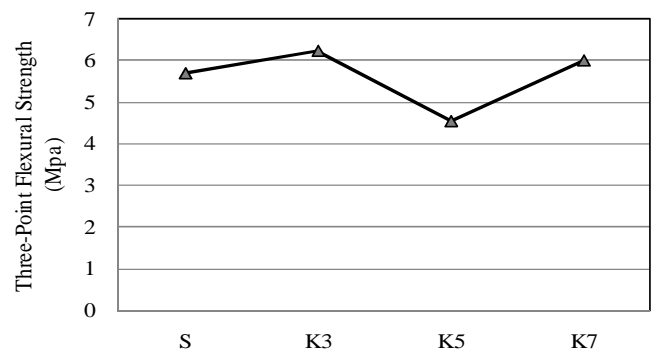

Figure 8. Three-point flexural strength of the specimens

\section{CONCLUSIONS}

Four concrete mix designs were casted. One of the mixtures was used as control mixture, which did not have cuttlebone powder. 3,5 and $7 \%$ of cement content were substituted with cuttlebone powder in other mixtures. Nine cubes, one cylinder and one prism were casted to test compressive, tensile and three-point flexural strengths. The following conclusions can be drawn:

1. By substituting a portion of cement content with cuttlebone powder, it was seen that the slump of the concrete increased. Therefore, workability of the concrete increased. So, by reduction of water demand, the strength will increase.

2. All of the specimens with cuttlebone powder had lower weight compared to control specimens. Thus, by substituting a portion of cement with cuttlebone powder, lighter structure could be achieved.

3. Compressive strength of the specimens after 7, 14 and 28 days showed that by adding cuttlebone powder, the strength decreased. But compressive strength of the specimen with 3 percent cuttlebone powder was acceptable.

4. Splitting tensile strength of the specimens with cuttlebone powder was lower than control specimen. But tensile strength of $\mathrm{K} 3$ specimen with $3 \%$ of cuttlebone powder was acceptable.

5. By substituting 3\% of cement with cuttlebone powder, the maximum three-point flexural strength was achieved.

6. By substituting 3\% of cement with cuttlebone powder, slump and also three-point flexural strength increased. Moreover, the values of compressive and tensile strength were acceptable. It is worth noting that in this research program, water content of this specimen was the same as control specimen one. So, by decreasing water, which was concluded from the slump test, more acceptable strengths would be achieved.

\section{References}

Bentz, D.P., Ardani, A., Barrett, T., Jones, S.Z., Lootens, D., Peltz. M.A., Sato, T., Stutzman, P.E., Tanesi, J., and Weiss, W.J., 2015. Construction and Building Materials, vol. 75, pp. $1-10$.

Bizzozero, J., and Scrivener, K.L., 2015. Limestone reaction in calcium aluminate cement-calcium sulfate systems. Cement and Concrete Research, vol. 76, pp. 159-169.
Mirzabagheri, S., Vatankhah, F., Ziaee, Z., Derhamjani, G., Maharati, S., and Aslani, H., 2018. Performance of concrete by using albumen, yolk and milk. Journal of Applied Engineering Sciences, vol. 8, no. 21, pp. 67-72.

Naik, T.R., Canpolat, F., and Chun, Y.M., 2003. Limestone powder use in cement and concrete. Report No. CBU-2003-31, REP-525, Department of Civil Engineering and Mechanics College of Engineering and Applied Science the University of Wisconsin-Milwaukee.

Norman, M.D., and Reid, A., 2000. A Guide to Squid, Cuttlefish and Octopuses of Australasia. CSIRO Publishing.

Okeyinka, O.M., Oladejo, O.A., 2014. The influence of calcium carbonate as an admixture on the properties of wood ash cement concrete. International Journal of Emerging Technology and Advanced Engineering, vol. 4, no. 12, pp. 432-437.

Periasamy, K., and Mohankumar, G.C., 2016. Sea coral-derived cuttlebone reinforced epoxy composites: characterization and tensile properties evaluation with mathematical models. Journal of Composite Materials, vol. 50, no. 6, pp. 807-823.

Ramos, M.J., and Swan, C.W., 2017. The strength characteristics of mortar concretes containing synthetic lightweight aggregate and calcium carbonate. 2017 World of Coal Ash (WOCA) Conference.

Rexfort, A., and Mutterlose, J., 2006. Stable isotope records from Sepia officinalis-a key to understanding the ecology of belemnites? Earth and Planetary Science Letters. vol. 247 no. 3-4, pp. 212-221.

Sui, Y.W., Qiao, P.F., Tian, Q.B., Yue, X.T., and Li, J., 2018. Properties of RPC with calcium carbonate concrete waste powder. IOP Conf. Series: Materials Science and Engineering, 371, pp. 1-7.

Supit, S.W.M., and Shaikh, F.U.A., 2014. Effect of nano$\mathrm{CaCO} 3$ on compressive strength development of high volume fly ash mortars and concretes. Journal of Advanced Concrete Technology, vol. 12, pp. 178-186.

Tennis, P.D., Thomas, M.D.A., and Weiss, W.J., 2014. State-ofthe-art report on use of limestone in cements at levels of up to $15 \%$ (Errata Corrections), SN3148, Portland Cement Association, Skokie, Illinois, USA, 78 pages.

Wang, G., Lu, L., and Wang, S., 2012. Effects of shell and calcium carbonate on properties of portland cement. Advanced Material Research, vol. 450-451, pp. 495-498.

Weerdt, K.D., 2007. Ternary blended cements with fly ash and limestone; Part II: Limestone powder; State of the art. SINTEF Building and Infrastructure, COIN-Concrete Innovation Centre, Report no: SBF BK A07024. 38 pages.

Wongkeo, W., 2017. Effect of calcium carbonate on compressive strength and physical properties of alkali-activated lightweight concrete. Key Engineering Materials, vol. 751, pp. 550-555. 